\title{
Regional Variation of Human Skin Surface Temperature
}

\author{
Chan Mi Lee ${ }^{1,2, *}$, Seon-Pil Jin ${ }^{1,2,3, *}$, Eun Jin Doh ${ }^{1,2}$, Dong Hun Lee ${ }^{1,2}$, Jin Ho Chung ${ }^{1,2,3}$ \\ ${ }^{1}$ Department of Dermatology, Seoul National University Hospital, ${ }^{2}$ Institute of Human-Environment Interface Biology, Medical Research \\ Center, Seoul National University, ${ }^{3}$ Department of Biomedical Sciences, Seoul National University Graduate School, Seoul, Korea
}

\section{Dear Editor:}

In addition to ultraviolet irradiation, heat causes skin aging, called thermal aging ${ }^{1}$. The reliable acquisition of regional skin surface temperature (SST), especially for the exposed area, is important to characterize thermal aging as well as to obtain physiological reference values.

A century ago, Benedict et al. ${ }^{2}$ reported the regional variation of SST of 28.1 (calf) $-34.7^{\circ} \mathrm{C}$ (waist) in a normallyclothed woman at about $17^{\circ} \mathrm{C}$. Other following studies described that the head had the highest skin temperature ${ }^{3}$ and recently, that the neck has a higher skin temperature than the forearm in the younger individuals ${ }^{4}$.

Although regional SST was previously reported ${ }^{2-4}$, these studies had limitations including a small number of participants (only one or two), no control of the environmental conditions (temperature and/or humidity) ${ }^{3,4}$, limited body regions, or technical limitations of the thermometer used such as improper skin contact or lack of dynamic measurement ${ }^{2}$. While more recent studies were performed in more tightly regulated environmental conditions ${ }^{5,6}$, these studies did not address regional SST. Therefore, we examined mean SST by measuring the temperature of 15 representative exposed body sites. To measure the temperature

Received September 20, 2017, Revised April 23, 2018, Accepted for publication May 31, 2018

Corresponding author: Dong Hun Lee, Department of Dermatology, Seoul National University Hospital, 101 Daehak-ro, Jongno-gu, Seoul 03080, Korea. Tel: 82-2-2072-2417, Fax: 82-2-742-7344, E-mail: ivymed27@snu.ac.kr ORCID: https://orcid.org/0000-0002-2925-3074

Jin Ho Chung, Department of Dermatology, Seoul National University Hospital, 101 Daehak-ro, Jongno-gu, Seoul 03080, Korea. Tel: 82-2-20722410, Fax: 82-2-742-7344, E-mail: jhchung@snu.ac.kr

ORCID: https://orcid.org/0000-0002-0582-6392

${ }^{*}$ These authors contributed equally to this work.

This is an Open Access article distributed under the terms of the Creative Commons Attribution Non-Commercial License (http://creativecommons. org/licenses/by-nc/4.0) which permits unrestricted non-commercial use, distribution, and reproduction in any medium, provided the original work is properly cited.

Copyright $($ c The Korean Dermatological Association and The Korean Society for Investigative Dermatology accurately and reliably, the participants were sufficiently acclimated in a temperature and humidity controlled room, and the digital thermometer with continuous monitoring system was employed. This study was approved by the Institutional Review Board of Seoul National University Hospital (IRB no. 1607-060-775), and conducted according to the Declaration of Helsinki.

Thirty (23 males, 7 females) healthy participants aged $25.2 \pm 1.8$ (mean \pm standard deviation) years were recruited. They had no other diseases related to blood circulation and metabolism, such as rosacea and thyroid diseases on history taking. This study was conducted within one month in the same season (in August, summer). The room in which participants were measured was tightly regulated by the temperature and humidity. The temperature and humidity were recorded at 3-minute intervals during the SST measurements. Study participants exposed their legs and arms after entering the room. After 15 minutes of acclimation, SST was measured by trained investigators using a digital thermometer (Fluke 51 II thermometer; Fluke, Everett, WA, USA) with a surface probe (model 80PK-3A), which could continuously monitor the temperature without giving a pressure to the skin. Participants maintained a supine position and the temperature was recorded once if it remained stable for more than 5 seconds. The SST of 8 facial regions (forehead, cheek, chin, ear, nose tip, eyelid, nasolabial area, and perioral area) and 7 body regions (anterior neck, palm, forearm, upper arm, sole, shin, and thigh) were measured (Fig. 1A). Each region was evaluated bilaterally except for the forehead, nose tip, and chin, where a single site was measured. The $\mathrm{R}$ program (ver. 3.0.1, https://www.R-project.org) was used for all statistical analyses, and the paired t-test was used to compare SST between both sides of the 12 regions. Only 3 regions (sole, shin, and thigh) were significantly different between the right and left side (Supplementary Table 1). The mean SST of both sides was used in 9 regions, in which no significant difference was seen between two sides. Among 15 regions, ten groups were categorized based on SST 
A

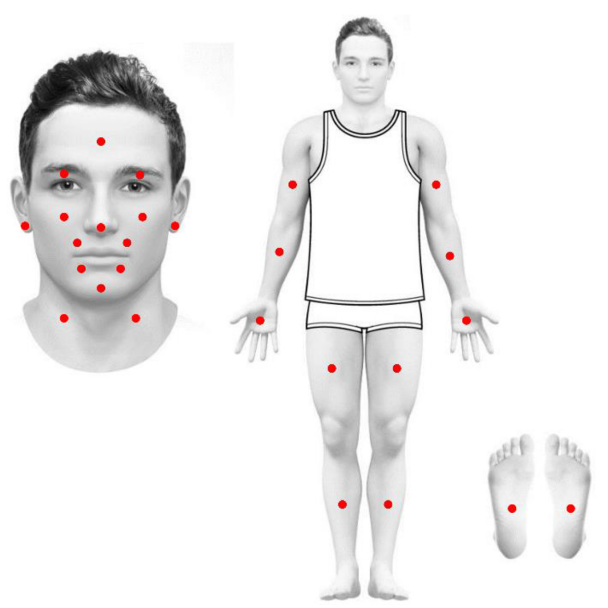

C

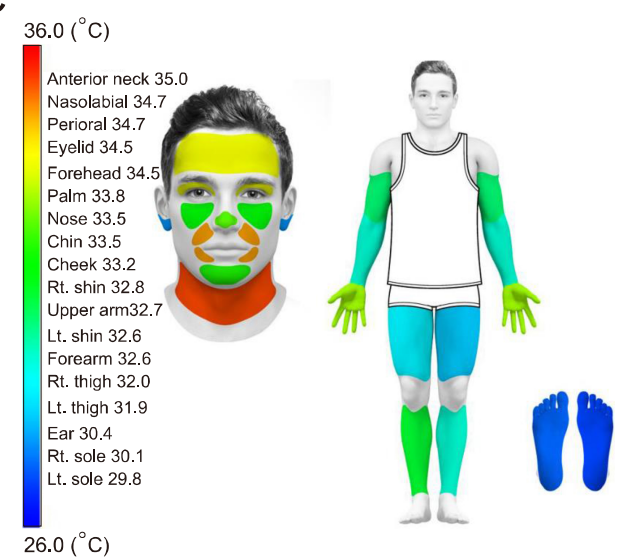

B
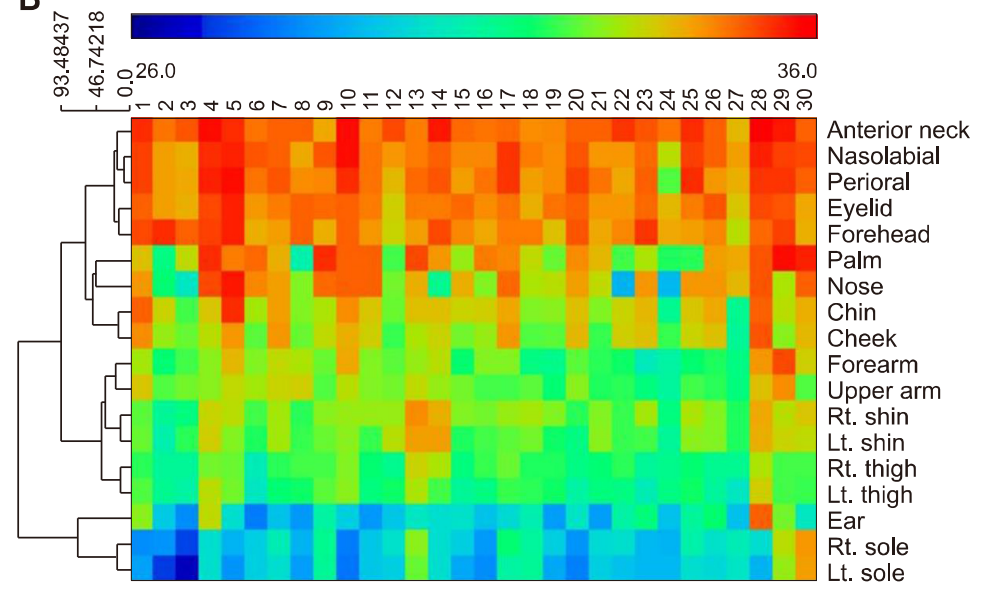

D

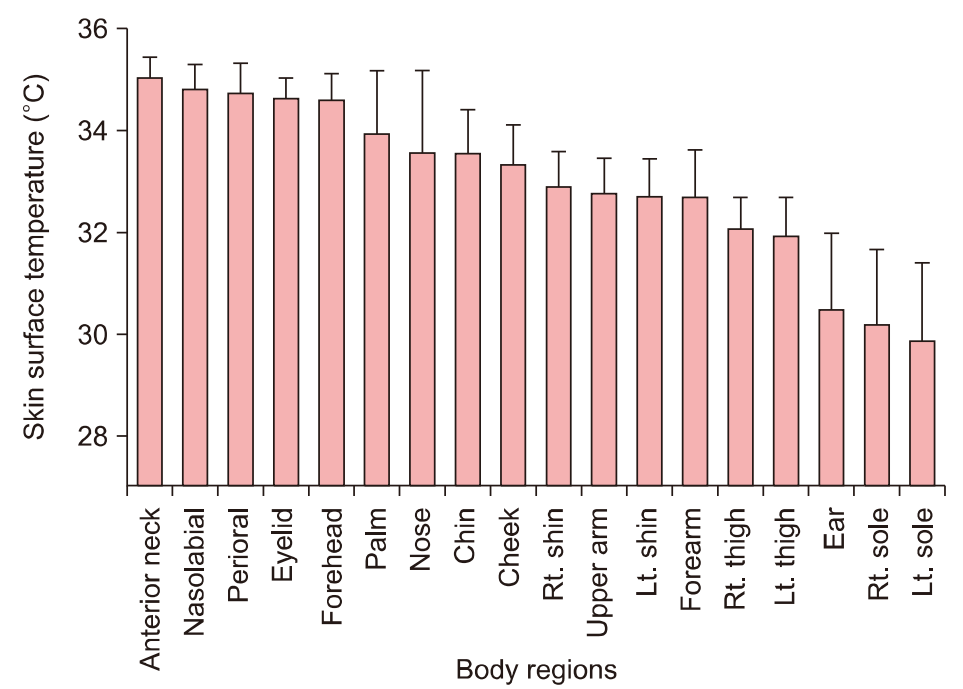

Fig. 1. (A) Schematic diagram of the regions that measured skin surface temperature (SST). As a whole, a total of 15 regions were measured. In the face, 8 regions were measured. And another 7 regions were the anterior neck, palm, forearm, upper arm, sole, shin, and thigh. Except for forehead, nose tip, and chin, both sides of each region were measured. (B) Heat map and hierarchical clustering of SST. Participants maintained a supine position and the temperature was recorded if it remained stable for more than 5 seconds. The color refers to SST. The lowest temperature was depicted as blue, and the highest as red $\left(26^{\circ} \mathrm{C} \sim 36^{\circ} \mathrm{C}\right)$. Hierarchical clustering was performed using the "Manhattan distance" metric. All participants were represented on the x-axis (1 $\sim 30)$, and body regions on the right (Rt.) y-axis. The left (Lt.) y-axis depicts hierarchical clustering. The top left figures show the mean distance between the regions in hierarchical clustering. (C) SST of the regions were depicted as different colors for quick reference. (D) The SST according to regions. The graphs show the average temperature and standard deviation.

similarity using the repeated measures ANOVA, followed by the Newman-Keuls multiple comparison test (Table 1). The heat map and pictorial diagram in Fig. 1B, C shows the overall summary of regional SST measurements from all participants. Moreover, the body regions of similar SST were clustered by hierarchical clustering through the Manhattan distance metric (Fig. 1B). The clustering results were similar to the categorization in Table 1. The regional variation of SST was exemplified by its descending order of temperature (Fig. 1D, Supplementary Table 2) and the pictorial diagram (Fig. 1C) revealed a region-dependent SST distribution from the anterior neck to left sole. During the period of measurement, the temperature and humidity were constantly regulated, with $24.4^{\circ} \mathrm{C} \pm 1.1^{\circ} \mathrm{C}$ and $46.3 \% \pm$ $6.5 \%$, respectively.

In this study, the anterior neck showed the highest SST of $35.0^{\circ} \mathrm{C} \pm 0.5^{\circ} \mathrm{C}$, while the left sole showed the lowest SST of $29.8^{\circ} \mathrm{C} \pm 1.6^{\circ} \mathrm{C}$. Interestingly, the SST of the right lower extremity was higher than that of the left lower extremity. SST is known to correlate with blood flow ${ }^{7}$, and exercise 
Table 1. Groups which show statistically similar temperature and the cases that show statistically significant difference between groups

\begin{tabular}{|c|c|c|c|}
\hline Group & Anatomical location & Mean \pm SD $\left({ }^{\circ} \mathrm{C}\right)$ & $\begin{array}{c}\text { Groups of which temperature is statistically } \\
\text { different versus each group }\end{array}$ \\
\hline 1 & Anterior neck, nasolabial, perioral, eyelid, forehead & $34.7 \pm 0.6$ & 1 vs. $2,3,4,5,6,7,8,9,10$ \\
\hline 2 & Palm & $33.8 \pm 1.3$ & 2 vs. $4,5,6,7,8,9,10$ \\
\hline 3 & Nose, chin & $33.5 \pm 1.3$ & 3 vs. $5,6,7,8,9,10$ \\
\hline 4 & Cheek & $33.2 \pm 0.9$ & 4 vs. $6,7,8,9,10$ \\
\hline 5 & Right shin & $32.8 \pm 0.7$ & 5 vs. $7,8,9,10$ \\
\hline 6 & Upper arm, left shin, forearm & $32.6 \pm 0.9$ & 6 vs. $7,8,9,10$ \\
\hline 7 & Right thigh, left thigh & $31.9 \pm 0.7$ & 7 vs. $8,9,10$ \\
\hline 8 & Ear & $30.4 \pm 1.5$ & 8 vs. 10 \\
\hline 9 & Right sole & $30.1 \pm 1.5$ & \\
\hline 10 & Left sole & $29.8 \pm 1.6$ & \\
\hline
\end{tabular}

SD: standard deviation.

training increases blood flow of the $\mathrm{skin}^{8}$. The relative high SST of the right side might be due to more blood flow on the right side, because most people are right-side dominant, which is associated with more blood flow. However, its physiological implication is doubtful and requires further research, considering the small difference of SST between right and left (see 95\% confidential interval in Supplementary Table 1).

Humidity is an important factor affecting SST $^{9}$. Previous studies have a limitation that they did not mention the controlled humidity ${ }^{2-4}$. On the other hand, the ambient temperature and humidity in the present study were tightly regulated.

There are some limitations to this study. The recruited participants were of a limited age range and showed skewed gender distribution. In addition, we did not simultaneously measure other factors such as skin blood flow, which might correlate with skin temperature.

We can conclude that the SST is different according to body region. The accepted skin temperature of $32^{\circ} \mathrm{C}$ to $-35^{\circ} \mathrm{C}^{2}$ is a vague description and the temperature of skin surface can exhibit about $5^{\circ} \mathrm{C}$ variation according to body region in the standard environment. These results are the most comprehensive measurements throughout exposed area. The SST values obtained in our study could be used as important reference values in the future studies. For instance, it would be interesting to investigate the changing SST according to the chronological aging. Skin blood flow may be affected by aging ${ }^{10}$, so the changing of temperatures by aging at the various body sites may vary. This study can elucidate the relation between skin blood flow and the surface temperature. Further studies are warranted to elucidate the factors contributing to regional differences in surface temperature.

\section{ACKNOWLEDGMENT}

This work has been supported by National Research Foundation of Korea (NRF) (NRF-2014M3A9D7070668).

\section{SUPPLEMENTARY MATERIALS}

Supplementary data can be found via http://anndermatol. org/src/sm/ad-31-349-s001.pdf.

\section{CONFLICTS OF INTEREST}

The authors have nothing to disclose.

\section{ORCID}

Chan Mi Lee, https://orcid.org/0000-0001-7907-0412

Seon-Pil Jin, https://orcid.org/0000-0002-8290-4278

Eun Jin Doh, https://orcid.org/0000-0002-0339-5146

Dong Hun Lee, https://orcid.org/0000-0002-2925-3074

Jin Ho Chung, https://orcid.org/0000-0002-0582-6392

\section{REFERENCES}

1. Cho S, Shin $\mathrm{MH}$, Kim YK, Seo JE, Lee YM, Park CH, et al. Effects of infrared radiation and heat on human skin aging in vivo. J Investig Dermatol Symp Proc 2009;14:15-19.

2. Benedict FG, Miles WR, Johnson A. The temperature of the human skin. Proc Natl Acad Sci U S A 1919;5:218-222.

3. Hardy JD, DuBois EF, Soderstrom GF. Basal metabolism, radiation, convection and vaporization at temperatures of 22 to $35^{\circ} \mathrm{C}$. J Nutr 1938;15:477-497.

4. Marrakchi S, Maibach HI. Biophysical parameters of skin: map of human face, regional, and age-related differences. Contact Dermatitis 2007; 57:28-34. 
Brief Report

5. Mitchell D, Wyndham $\mathrm{CH}$, Atkins AR, Vermeulen AJ, Hofmeyr HS, Strydom NB, et al. Direct measurement of the theramal responses of nude resting men in dry environments. Pflugers Arch 1968;303:324-343.

6. Yosipovitch G, Xiong GL, Haus E, Sackett-Lundeen L, Ashkenazi I, Maibach HI. Time-dependent variations of the skin barrier function in humans: transepidermal water loss, stratum corneum hydration, skin surface $\mathrm{pH}$, and skin temperature. J Invest Dermatol 1998;110:20-23.

7. Rubinstein EH, Sessler DI. Skin-surface temperature gradients correlate with fingertip blood flow in humans. Anesthesiology 1990;73:541-545.
8. Simmons GH, Wong BJ, Holowatz LA, Kenney WL. Changes in the control of skin blood flow with exercise training: where do cutaneous vascular adaptations fit in? Exp Physiol 2011;96:822-828.

9. Brebner DF, Kerslake DM, Waddell JL. The effect of atmospheric humidity on skin temperature \& sweat rates of resting men at two ambient temperatures. J Physiol 1958; 144:299-306.

10. Waller JM, Maibach HI. Age and skin structure and function, a quantitative approach (I): blood flow, $\mathrm{pH}$, thickness, and ultrasound echogenicity. Skin Res Technol 2005; $11: 221-235$.

\title{
Adiponectin Promotes Caspase-14 Expression in Normal Human Epidermal Keratinocytes
}

\author{
Sun Young Choi*, Min Jeong Kim ${ }^{1, *}$, Ji Yeon Hong ${ }^{1}$, Kui Young Park ${ }^{1}$, Seong Jun Seo ${ }^{1}$ \\ Department of Dermatology, Inje University Seoul Paik Hospital, Inje University College of Medicine, ${ }^{1}$ Department of Dermatology, \\ Chung-Ang University College of Medicine, Seoul, Korea
}

\section{Dear Editor:}

Filaggrin (FLG) and its high molecular-weight precursor profilaggrin (proFLG) are filament-associated proteins that aggregate keratin fibers in keratinocytes. The cellular processing of proFLG and FLG provides an important material source of natural moisturizing factors (NMF), and multiple proteolytic enzymes including peptidylarginine deiminase (PAD) 1, PAD 3, caspase-14, calpain 1 and bleomycin hydrolase have been implicated in their proteolytic process- ing $^{1}$. Among these proteases, caspase- 14 is considered the key enzyme, as it is thought to directly cleave the FLG repeat in preparation for complete breakdown by other enzymes $^{2}$. Adiponectin, an adipokine secreted from adipocytes, has primary effects on energy metabolism and anti-diabetic in nature. It has been well known that adiponectin also has anti-inflammatory effects ${ }^{3}$.

Recently, there are a few reports investigating the effects of adiponectin on skin. It has been shown that adiponectin

Received March 20, 2018, Revised June 4, 2018, Accepted for publication June 12, 2018

Corresponding author: Seong Jun Seo, Department of Dermatology, Chung-Ang University Hospital, 102 Heukseok-ro, Dongjak-gu, Seoul 06973, Korea. Tel: 82-2-6299-1525, Fax: 82-2-6299-1718, E-mail: drseo@cau.ac.kr ORCID: https://orcid.org/0000-0003-2915-839X

Kui Young Park, Department of Dermatology, Chung-Ang University Hospital, 102 Heukseok-ro, Dongjak-gu, Seoul 06973, Korea. Tel: 82-2-6299-1530, Fax: 82-2-6299-1718, E-mail: kyky@caumc.or.kr ORCID: https://orcid.org/0000-0001-5965-1754

* These authors equally contributed as first authors.

This is an Open Access article distributed under the terms of the Creative Commons Attribution Non-Commercial License (http://creativecommons.org/ licenses/by-nc/4.0) which permits unrestricted non-commercial use, distribution, and reproduction in any medium, provided the original work is properly cited.

Copyright (C) The Korean Dermatological Association and The Korean Society for Investigative Dermatology 
Supplementary Table 1. Whether the surface temperature shows difference between right and left according to the body regions

\begin{tabular}{|c|c|c|}
\hline Skin surface temperature between the right and left & Anatomical location & $95 \%$ confidence interval $\left({ }^{\circ} \mathrm{C}\right)$ \\
\hline Not significantly different & $\begin{array}{l}\text { Cheek, ear, eyelid, nasolabial, perioral, anterior } \\
\text { neck, palm, forearm, upper arm }\end{array}$ & \\
\hline \multirow[t]{3}{*}{ Significantly different $(p<0.05$, right $>$ left $)$} & Sole & $0.21,0.50$ \\
\hline & Shin & $0.08,0.35$ \\
\hline & Thigh & $0.0074,0.29$ \\
\hline
\end{tabular}


Brief Report

Supplementary Table 2. Skin surface temperature of each region from 30 volunteers

\begin{tabular}{lc}
\hline Anatomical location & Mean $\pm \mathrm{SD}\left({ }^{\circ} \mathrm{C}\right)$ \\
\hline Anterior neck & $35.0 \pm 0.5$ \\
Nasolabial & $34.7 \pm 0.5$ \\
Perioral & $34.7 \pm 0.7$ \\
Eyelid & $34.5 \pm 0.4$ \\
Forehead & $34.5 \pm 0.6$ \\
Palm & $33.8 \pm 1.3$ \\
Nose & $33.5 \pm 1.6$ \\
Chin & $33.5 \pm 0.9$ \\
Cheek & $33.2 \pm 0.8$ \\
Right shin & $32.8 \pm 0.7$ \\
Upper arm & $32.7 \pm 0.7$ \\
Left shin & $32.6 \pm 0.8$ \\
Forearm & $32.6 \pm 1.0$ \\
Right thigh & $32.0 \pm 0.7$ \\
Left thigh & $31.9 \pm 0.8$ \\
Ear & $30.4 \pm 1.6$ \\
Right sole & $30.1 \pm 1.5$ \\
Left sole & $29.8 \pm 1.6$ \\
\hline
\end{tabular}

SD: standard deviation. 